\title{
The effectiveness of road closures and deactivations at reducing traffic: A case of resource roads used for recreational activities in Ontario, Canada
}

\author{
by Len M. Hunt ${ }^{1, *}$ and Matthew Hupf ${ }^{1}$
}

\begin{abstract}
We investigated the effectiveness of different approaches at limiting motorized vehicle traffic on unpaved roads designed to support forestry operations (i.e., resource roads). The approaches (i.e., year-round closure, seasonal closure, deactivation, and deactivation and closure) were employed to provide non-road-based opportunities for people to pursue outdoor recreation and nature-based tourism activities by deterring hunters and others from using motorized vehicles to access areas beyond a road closure/deactivation. Using the case of weekend traffic on single-lane resource roads in northern Ontario, Canada during the gun portion of the moose (Alces alces) hunting season, we developed and investigated three general hypotheses. The first hypothesis that closure and/or deactivation approaches significantly reduce traffic on these resource roads was supported. In fact, we estimated that on average these approaches should reduce about $78 \%$ of traffic. No support existed for the second hypothesis that the effectiveness of these approaches depends on road quality. The third hypothesis was supported that differences exist in the effectiveness of the four road closure and/or deactivation approaches to reduce traffic on resource roads. A year-round closure was amongst the least while a seasonal road closure was amongst the most effective approach to reduce traffic on these roads.
\end{abstract}

Keywords: resource management, road ecology, compliance

\section{RÉSUMÉ}

Nous avons étudié l'efficacité de différentes approches pour limiter la circulation de véhicules motorisés sur les routes non pavées conçues pour les opérations forestières (par ex., les chemins d'accès). Les approches (par ex., fermeture à lannée longue, fermeture saisonnière, mise hors service et mise hors service et fermeture) ont été utilisées pour offrir des possibilités de se déplacer sans utiliser de route aux personnes qui entreprennent des activités récréatives en plein air et décotourisme tout en incitant les chasseurs et autres utilisateurs à se déplacer sans véhicule moteur dans les zones se retrouvant après la section de route fermée ou mise hors service. Au moyen de lexemple de la circulation lors de fins de semaine sur des chemins forestiers à une voie dans le nord de l'Ontario au Canada, au cours des jours de chasse au fusil de la période de chasse à lorignal (Alces alces), nous avons élaboré et étudié trois hypothèses générales. La première hypothèse voulant que lapproche impliquant la fermeture accompagnée ou non de mise hors service réduise de façon significative la circulation sur ces chemins forestiers savère fondée. En effet, nous avons estimé quen moyenne ces approches devraient réduire la circulation de $78 \%$. Nous navons trouvé aucun point appuyant la deuxième hypothèse voulant que lefficacité de ces approches dépende de la qualité de la route. La troisième hypothèse s’appuyait sur le fait quon retrouve des différences au niveau de lefficacité des quatre approches de fermeture ou de mise hors service pour réduire la circulation sur les chemins d’accès. La fermeture à lannée longue sest avéré être la moins efficace, tandis que la fermeture saisonnière a été lapproche la plus efficace pour réduire la circulation sur ces chemins.

Mots clés : aménagement des ressources, écologie de la route, conformité

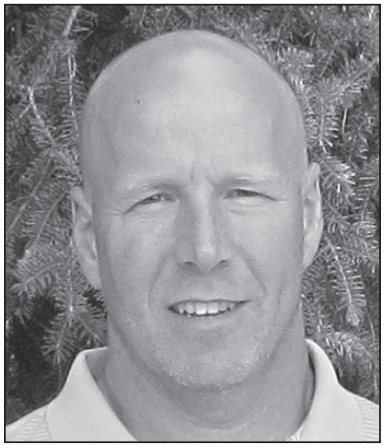

Len M. Hunt

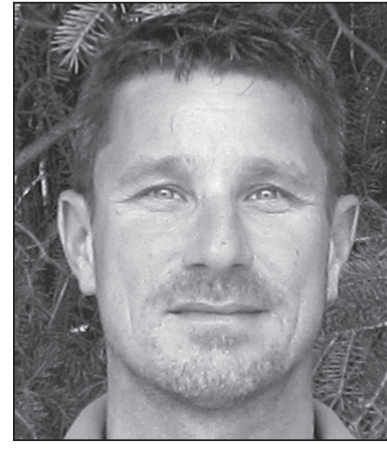

Matthew Hupf

\section{Introduction}

Roads can induce many potential negative effects on social and ecological systems. In fact, Forman (2002: viii) described the effects from roads as "the sleeping giant of biological conservation". Researchers have responded to this description by conducting applied research under the banner of road ecology (Forman et al. 2003). This research includes both studies of effects from roads and of ways to avoid, mitigate or reduce these effects (van der Ree et al. 2011). Consequently, researchers are increasingly calling on managers and others to integrate road ecology when managing transportation networks (Coffin 2007) and natural resources (Robinson et al. 2010).

${ }^{1}$ Centre for Northern Forest Ecosystem Research, Ontario Ministry of Natural Resources and Forestry, 955 Oliver Road, Thunder Bay, Ontario P7B 5E1.

*Corresponding author. E-mail: len.hunt@ontario.ca 
An effective way to categorize the effects of roads on ecological systems is by placement and use themes (Robinson et al. 2010). The act of placing a road can fragment wildlife habitat, change wildlife behaviors, alter physical environments, and disturb hydrological systems (see Forman et al. 2003). These changes can arise even if people never use the road.

Other effects from roads arise from human use (e.g., motorized vehicle use) of these roads. While researchers have long known that vehicles kill a large number of wildlife (e.g., Bellis and Graves 1971, Oxley et al. 1974), more recent studies also stress that many wildlife species avoid traffic sounds (e.g., Fahrig and Rytwinski 2009). These avoidance effects have encouraged researchers to identify thresholds for traffic volumes that induce these effects (Charry and Jones 2010).

Use effects also arise from the behaviours of road travelers. Some individuals affect fish and wildlife populations by using roads to introduce (accidentally or purposefully) aquatic species (Carpenter et al. 2007) and to exploit wildlife (Wilkie et al. 2008).

These potential use effects are especially important to consider for resource road networks. Resource roads, which are unpaved roads that enable natural resource activities such as forestry or mineral exploration, are important because these networks often expand over time resulting in increasing access to formerly remote areas (Daigle 2010). To reduce or mitigate the ecological and social ${ }^{1}$ effects of resource road use, a need exists to identify and apply approaches that reduce traffic volumes on these roads.

Resource managers have responded to this need by adopting closure, deactivation, and/or removal approaches to reduce traffic volumes on resource roads. Road closures prohibit individuals from using an existing road. An advantage of closures is that one can prohibit specific users, activities, areas, or times of year while maintaining the road's function for authorized activities and users. Road deactivation represents an unplugging of a road from a larger network. For example, one can place an earthen berm on a road that blocks the road from the larger road network. Finally, one can use road removal techniques such as road ripping or road obliteration to address both concerns with placing and using roads. Removal differs from deactivation as removed roads are extensively altered to make the entire road impassable to vehicles.

Researchers have provided little guidance about effective yet pragmatic approaches to manage the negative effects from placing and using roads (Roedenbeck et al. 2007). Closing, deactivating, and removing roads offer planners and resource managers several options to reduce these effects in resource road settings. However, research that assesses the effectiveness of these options is largely published in reports with assessments based on field inspections of roads and/or interviews with agency staff and publics (e.g., Hammer 2001, Henschel 2003). As an exception, Hunt and Hosegood (2008) used more objective traffic-counting data to help determine the effectiveness of a single option to manage use. They found that seasonal road closures were largely effective at removing traffic from resource roads near Wawa in northeastern Ontario, Canada. Given the small spatial extent of their study and their focus on only one

\footnotetext{
${ }^{1}$ The economic livelihood of nature-based tourism operators often relies on "values" such as remoteness and high abundance of fish and wildlife (OMNR 2001). Expansions to the size and use of resource road networks can deteriorate these attributes.
}

type of road closure, a significant research gap remains in understanding the effectiveness of road closure and deactivation approaches at reducing traffic volumes. ${ }^{2}$

We attempt to fill this gap by assessing the relative effectiveness of four types of road closures and deactivations (i.e., year-round and seasonal closures, deactivations, and combined deactivations and closures) at reducing traffic on resource roads located on public lands in northern Ontario during a time of high recreational activity (i.e., the moose [Alces alces] hunting season).

The need to curb traffic on resource roads that support recreational activities (i.e., recreational traffic) relates to the goals of protecting nature-based tourism and recreation values (OMNR 2001, 2007). This protection is necessary as some tourists/recreationists access hunting areas by means other than motorized vehicle travel on resource roads. Consequently, hunters who access these same areas by using motorized vehicles on resource roads might reduce wildlife abundance and diminish the perceived "remoteness" of an area through increasing sounds, sights, and conflicts with the tourists. Therefore, road closures and deactivations are used to spatially segregate road-based hunters from other tourist and recreational hunters (Hunt and Hosegood 2008).

We developed the following hypotheses:

H1: Treating resource roads with closure and/or deactivation approaches will significantly reduce traffic

H2: Treating resource roads with closure and/or deactivation approaches will be most effective at reducing traffic when roads are of poorest quality.

H3: The effectiveness of reducing traffic on resource roads will vary among the different closure and/or deactivation treatments.

H3a: Treating resource roads with a seasonal closure is more effective at reducing traffic than treating roads with a year-round closure.

H3b: Treating resource roads with a combined deactivation and closure is the most effective treatment to reduce traffic.

The first hypothesis is self-evident. The real question here is what percentage of traffic on resource roads is reduced by the closure and deactivation treatments. The second hypothesis focuses on whether this percentage is related to the quality of roads. We know that road quality should affect individuals' choices of hunting sites and consequently traffic levels during the moose hunting season (e.g., Boxall and McNab 2000, Haener et al. 2001). As road quality deteriorates, it becomes relatively more costly and difficult for individuals to access sites to hunt for moose. We suspect that individuals incurring these increased costs will be more deterred when confronted with a closure and/or deactivation treatment. Consequently, we believe that the effectiveness of the closure and/or deactivation treatments will be greatest when road quality is poorest.

The third hypothesis posits that the different closure and deactivation treatments will have differing levels of effectiveness at reducing traffic on resource roads. Hypotheses $3 a$ and $3 b$ are nested under $\mathrm{H} 3$. $\mathrm{H} 3 a$ suggests that a seasonal closure of resource roads should be more effective at reducing traffic than would be a year-round closure. This hypothesis arises from the

${ }^{2}$ Road removal by definition should remove all traffic and, thus, it is not necessary to study the effectiveness of road removal approaches at removing traffic. 
finding that publics are more accepting of seasonal than they are of year-round closures of resource roads (McFarlane et al. 2007, Mihell and Hunt 2011). Consequently, this greater acceptance should result in higher compliance with seasonal than year-round closures of roads. Finally, $H 3 b$ suggests that combining both deactivation and closure approaches should represent the most effective treatment for reducing traffic. This hypothesis stems from speculation by others (OMNR 2001, Henschel 2003) that multiple treatments are more effective than single treatments at reducing traffic on resource roads.

\section{Methods}

\section{Study area}

The empirical data for this study came from traffic counts on resource roads in northern Ontario. Only resource roads located on publicly owned lands outside of parks and protected areas (i.e., on Crown lands) were included here.

Roads were classified into five different types and two quality dimensions. The types included open, year-round closed, seasonally closed, deactivated, and deactivated and closed roads (Fig. 1). As the name suggests, a seasonally closed road was open for public travel during some portion of the year. Authority to close a road came from the OMNR District Manager through section 28 of the Public Lands Act

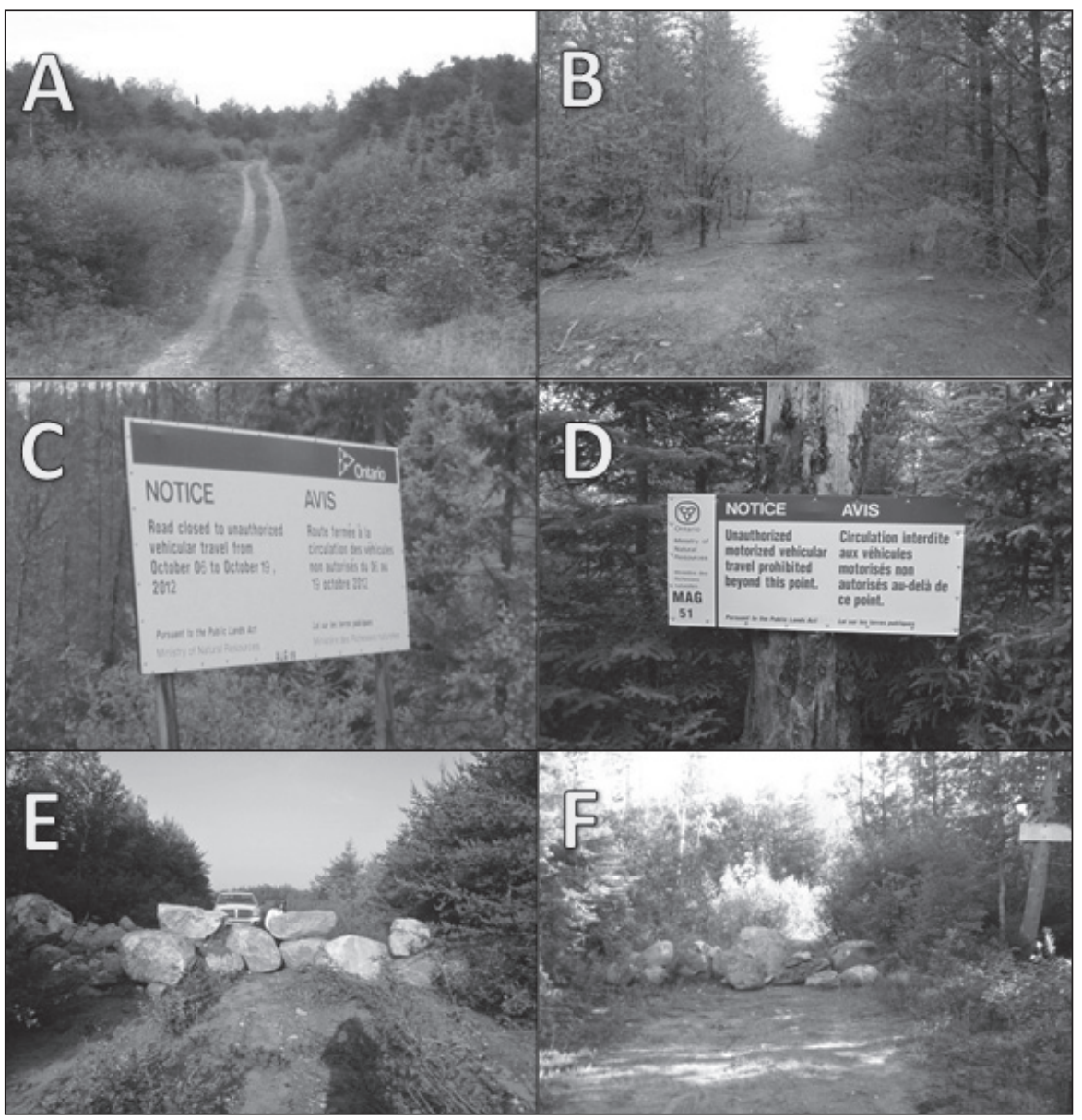

Fig. 1. Illustrative examples of different type of treatments and qualities of resource roads in northern Ontario. (A - Open, high-quality, single-lane road; B - Open, low-quality, single-lane road, C - seasonal closure sign; D - permanent closure sign; E - deactivated road; F - combined deactivated and closed road)
(1990). The signage on the closed roads was not always the same but generally stated that a road was closed to all unauthorized public vehicular travel. Authorized users included individuals who were pursuing economic-based activities such as forest management and mineral prospecting. While the penalty for non-compliance with the road closure could range up to $\$ 10000$, the typical out-of-court settlement was much lower.

Deactivated roads had impediments such as earthen or rock berms placed across the road with ditching and/or culvert removal to prevent or limit motorized vehicle traffic. Deactivated and closed roads included a sign-based closure and impediments placed across the roads. Finally, open roads were simply open for public travel (i.e., the road was not treated to limit traffic volumes).

Roads were initially classified by four categories of quality. Primary roads were at least $7.5 \mathrm{~m}$ wide while branch roads were between $5.0 \mathrm{~m}$ and $7.4 \mathrm{~m}$ wide as measured by the travelled surface. The $5.0-\mathrm{m}$ width threshold approximates the minimum width needed for two vehicles to pass (i.e., to allow two-lane traffic). For single-lane roads $(<5.0$ $\mathrm{m}$ width), high-quality roads were qualitatively assessed to be drivable by automobile while low-quality roads were not. For example, encroaching vegetation, rutting, and wet areas all would move a single-lane road into a low-quality category (see Fig. 1). The evaluations of roads were conducted by a small set of people including an author who has extensive experience with driving on resource roads in Ontario.

We sought to have a full coverage of all road quality and treatment types. However, very few primary and branch roads were deactivated or deactivated and closed $(n=4)$. Even for the seasonally closed road type, only five branch and no primary roads were present. Therefore, we restricted the focus to the two classes of single-lane unpaved roads that were classified as high or low quality.

A total of 185 low- or high-quality, single-lane roads were selected across Crown lands in Ontario (Fig. 2). Of the 185 selected roads, 104 were classified as open. This relatively high number of open roads arose because we made use of data for some open roads that were monitored for a different project. Of the remaining 81 (treated) roads, 23 were seasonal closures, 16 were year-round closures, 20 were deactivated, and 22 were closed and deactivated. The differences in these numbers reflect the relative scarcity of the different types of treatments for these resource roads. Given this scarcity, we conducted a near census of sites for the treatments rather 


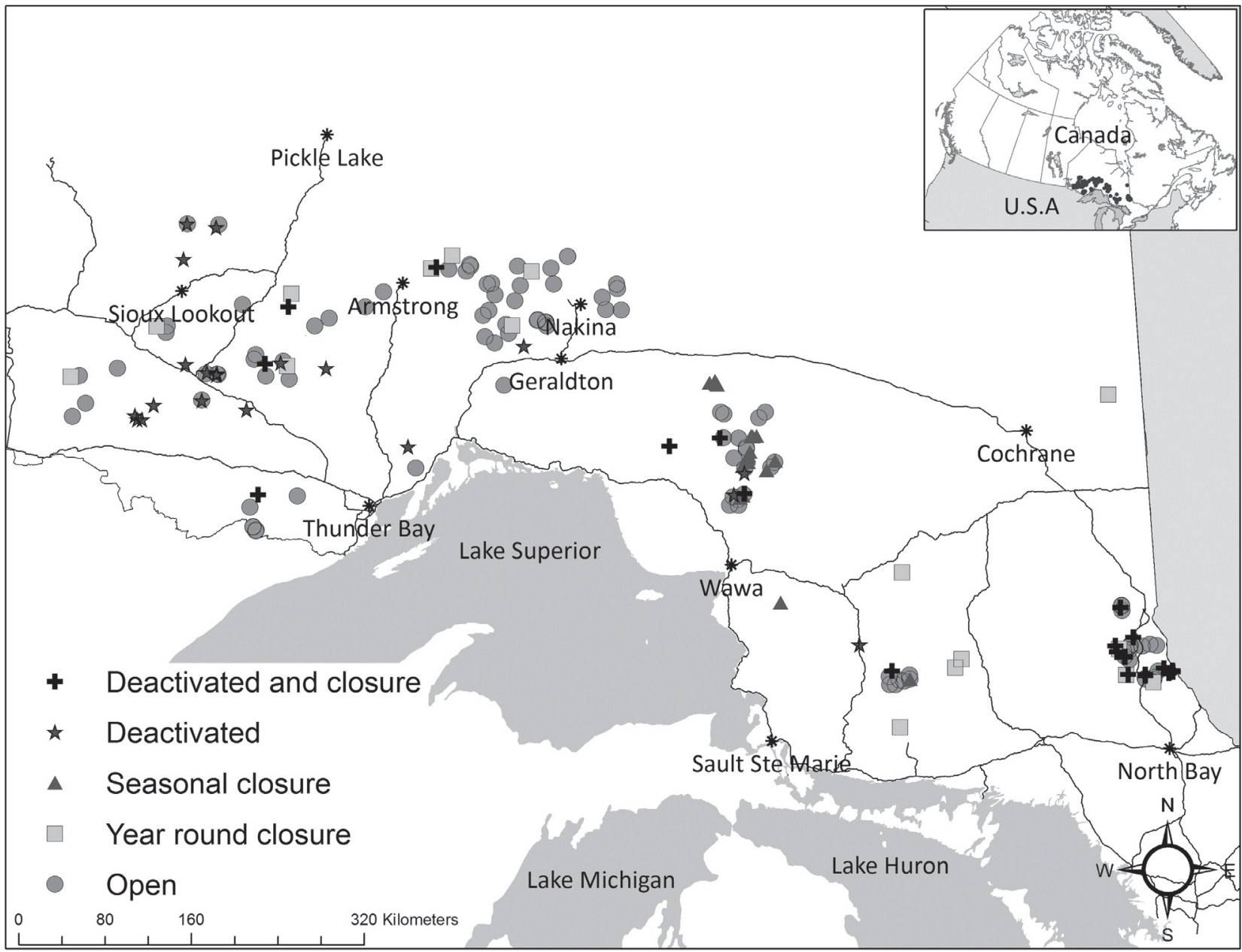

Fig. 2. Study area and locations of monitored high and low-quality resource roads in northern Ontario.

than a random sample. This scarcity also led to spatial concentrations of treatment types as different administrative districts tended to favour different approaches to eliminate or to reduce traffic on roads.

\section{Traffic measurement}

For each selected road, road use was measured with micro-magnetometer, traffic-counting devices from TRAFx Research Ltd. These devices, which one can bury to prevent vandalism, detect moving ferrous objects such as vehicles near the units (US Department of Transportation 2006). Tests throughout northern Ontario at 31 sites with devices placed on opposite sides of primary and branch resource roads suggested that the miss rate of the counters was approximately $6 \%$. Further and more extensive tests with the devices revealed that all passenger vehicles within $5 \mathrm{~m}$ and all terrain vehicles (ATVs) within $2 \mathrm{~m}$ of a device were detected. Therefore, we buried the traffic counters in the centre of the road or trail when expecting ATV traffic and at the side of a road when expecting passenger vehicles. During pretesting, the devices had a tendency to double-count occurrences of some larger-sized vehicles. Therefore, counts were considered unique only if they occurred 10 or more seconds after the previous count. While this lag of ten seconds might seem large, tests on primary resource roads suggests that this lag would result in no more than a $6 \%$ under-reporting of vehicle counts.
Given a limited number of micro-magnetometers, traffic data from both ATVs and passenger vehicles were collected at each road for at least one year between 2006 and 2012. We averaged the daily counts at the sites for the first five weekends of the gun hunt season for moose (Alces alces) ${ }^{3}$. The gun hunting season for moose was chosen because past unpublished research suggested that recreational traffic on resource roads is at its maximum during this period and weekends are the preferred days for people to hunt for moose. The focus on weekend days during the moose hunting season also served to reduce the amount of authorized traffic occurring at the roads (i.e., for safety reasons, authorized users tend to avoid travelling on weekend days during the moose hunting season). Roads with obvious economic activities occurring on weekends, such as forest management, were not included in the analyses. Given the focus on the gun hunting season for moose, we classified roads as seasonally closed if the road was closed during part of the moose hunting season up to a maximum of two weeks. For the seasonally closed roads, average daily traffic was only calculated from weekend days when the road was closed.

${ }^{3}$ The starting dates for the gun hunt in northern Ontario vary by wildlife management unit with the start date either on the Saturday closest to September 17 or to October 8 . 
Table 1. Average daily traffic counts (and standard deviations) for single-lane (highand low-quality) unpaved roads in northern Ontario during the first five weekends of the moose hunting season from 2006-2012 by treatment type

\begin{tabular}{lcccc}
\hline Treatment & Road type & N & Mean & $\begin{array}{c}\text { Standard } \\
\text { deviation }\end{array}$ \\
\hline Open & high-quality & 58 & 6.2 & 4.4 \\
Open & low-quality & 46 & 2.0 & 2.0 \\
Year-round closure & high-quality & 9 & 2.1 & 1.8 \\
Year-round closure & low-quality & 7 & 1.4 & 1.6 \\
Seasonal closure & high-quality & 7 & 0.9 & 0.5 \\
Seasonal closure & low-quality & 16 & 0.1 & 0.3 \\
Deactivation & high-quality & 3 & 1.0 & 0.9 \\
Deactivation & low-quality & 17 & 0.5 & 0.6 \\
Deactivation and closure & high-quality & 6 & 0.7 & 0.4 \\
Deactivation and closure & low-quality & 16 & 0.3 & 0.3 \\
\hline
\end{tabular}

Table 2. Regression parameter estimates and standard errors (corrected for heteroscedasticity) for predicting average daily traffic count on unpaved single-lane roads in northern Ontario, 2007-2012 during the first five weekends of the regular moose hunting season

\begin{tabular}{lccc}
\hline Parameter & Estimate & $\begin{array}{c}\text { Standard } \\
\text { error }\end{array}$ & P \\
\hline Intercept & 1.932 & 0.282 & $<0.01$ \\
Treated road (treated coded as 1 and open as 0) & -1.495 & 0.300 & $<0.01$ \\
High road quality (high coded as 1 and low as 0) & 4.228 & 0.642 & $<0.01$ \\
$\begin{array}{l}\text { Interaction between treated road and high } \\
\text { road quality }\end{array}$ & -3.351 & 0.699 & $<0.01$ \\
\hline
\end{tabular}

\section{Statistical analyses}

We evaluated the hypotheses with null hypothesis testing. For $\mathrm{H} 1$ and $\mathrm{H} 2$, the tests came from results of a regression-based model that accounted for unequal error variances among open and treated roads. The average daily traffic counts at the roads were predicted from the general road type (open or treated), road quality (high- or low-quality road) and the interaction between the general road type and road quality. $H 1$ was accepted if traffic on open sites was higher than for treated sites and the parameter estimate for the general road type was statistically significantly different from zero $(\alpha=0.05)$. From this regression, we used Monte Carlo simulation (Krinsky and Robb 1986) to estimate the mean and confidence interval of the general road type effect on average daily traffic for both high- and lowquality roads. We expressed the mean and confidence intervals as estimated percentages of traffic removed from a treatment for high- and low-quality roads. If the estimated percentages and confidence intervals were higher for the low- than high-quality road contexts, we accepted $\mathrm{H} 2$.

The distribution of high- and low-quality roads differed among the four treatment types. Testing differences in the mean estimates for these treatments would be misleading if road quality affected traffic volumes. Therefore, the average daily counts at all treated sites were converted into percentages. The percentage equaled one minus the observed divided by expected counts (i.e., the estimated percentage of traffic reduced by the treatment). The expected traffic counts or counterfactuals were based on mean estimates from the open roads for both highand low-quality road contexts. If the resulting percentage was negative (i.e., observed count exceeded the expectation), it was set to zero implying that the control was completely ineffective at reducing traffic. From these percentages, we used non-parametric statistical tests to evaluate the relative effectiveness of the four treatments. The main test was a KruskalWallis $\mathrm{H}$-test. If the probability for the H-test was less than 0.05 , we accepted $H 3$. In this case, we also conducted pairwise comparisons among the four different treatments with Mann Whitney U-tests with Bonferroni adjusted probabilities at $\alpha=0.05$. H3a was accepted if the relative reduction in traffic was statistically significantly higher for a seasonal than year-round closure treatment. $H 3 b$ was accepted if the relative reduction in traffic was statistically significantly higher for a combined deactivation and closure treatment than for all other treatment types. The differences in relative effectiveness of the four treatments were also displayed with box plots representing plus and minus one standard error of and the $95 \%$ confidence interval for the mean estimates.

\section{Results}

Open roads had the highest average daily traffic counts on weekend days during the hunting season (Table 1). Of the treated roads, year-round closed roads had the highest average daily traffic counts. Very few other differences were apparent for the other treatments. As expected, high-quality roads had higher average daily traffic counts than did low-quality roads.

Given the presence of heteroscedasticity (Breusch-Pagan Test: $\chi^{2}=111.9, \mathrm{df}=3, p<0.01$ ), a multiple regression model was estimated with heteroscedasticity-consistent standard errors (White 1980). The adjusted $R^{2}$ for the final model was 0.43 (Table 2). The general treated road type effect was negative and statistically significantly different from zero $(p<0.01)$. This result led us to accept $H 1$. Road quality was positive and statistically significantly different from zero implying that higher-quality roads were estimated to have more traffic. The sign on the interaction term was negative and statistically significantly different from zero $(p<0.01)$. This result implied that more traffic was reduced when a treatment was combined with a high- than lowquality road.

A significant amount of traffic was reduced on roads that were treated. For high-quality roads, the estimated reduction in traffic was $78 \%$ with a $95 \%$ confidence interval between $69 \%$ and $87 \%$. For low-quality roads, the estimated reduction in traffic was $77 \%$ with a $95 \%$ confidence interval of between $63 \%$ and $88 \%$. These results led us to reject $H 2$ that the relative effectiveness of approaches to reduce traffic will negatively relate to road quality.

Two of the 81 treated roads had an estimated negative value for the percentage of reduction in traffic. For these cases, the percentages were set to zero, which implied that the treatment was completely ineffective at reducing traffic. The average 
Table 3. Results of Mann-Whitney U-test comparisons between different pairs of treatments for expected traffic reduction on single-lane, unpaved roads in northern Ontario, 2007-2012 during the first five weekends during the regular moose hunting season.

\begin{tabular}{lccc}
\hline Treatment 1 & Treatment 2 & U & Pa \\
\hline Seasonal closure & year-round closure & 43.0 & $<0.01$ \\
Deactivation and closure & seasonal closure & 185.5 & 0.68 \\
Deactivation and closure & year-round closure & 67.0 & 0.01 \\
Deactivation and closure & deactivation & 179.0 & 1.00 \\
Seasonal closure & deactivation & 140.0 & 0.23 \\
Year-round closure & deactivation & 90.5 & 0.25 \\
\hline
\end{tabular}

a Bonferroni adjusted probability

proportion of traffic reduction was $81 \%$ with a standard deviation of $25 \%$. A Kruskal Wallis-H test $\left(\chi^{2}=19.0, \mathrm{df}=3, p<0.01\right)$ supported $H 3$ that the percentages of reduction in traffic estimates differed among the four treatments.

Pairwise comparisons with Mann-Whitney U-tests supported $\mathrm{H} 3 \mathrm{a}$ that a seasonally closed road would be more effective at reducing traffic than would be a year-round closed road Table 3, Fig. 3). Consistent with $H 3 b$, a combined deactivation and closure treatment was statistically significantly more effective at reducing traffic than was a year-round closure treatment (Fig. 3). However, the results when comparing the combined deactivation and closure treatment to a seasonal closure or deactivation were not consistent with $H 3 b$. No other statistically significant differences in effectiveness at reducing traffic existed between other pairs of treatments.

\section{Discussion}

Motorized vehicle use on resource roads can result in many negative ecological effects (Forman et al. 2003). To contribute to the road ecology literature focused on mitigating and reducing

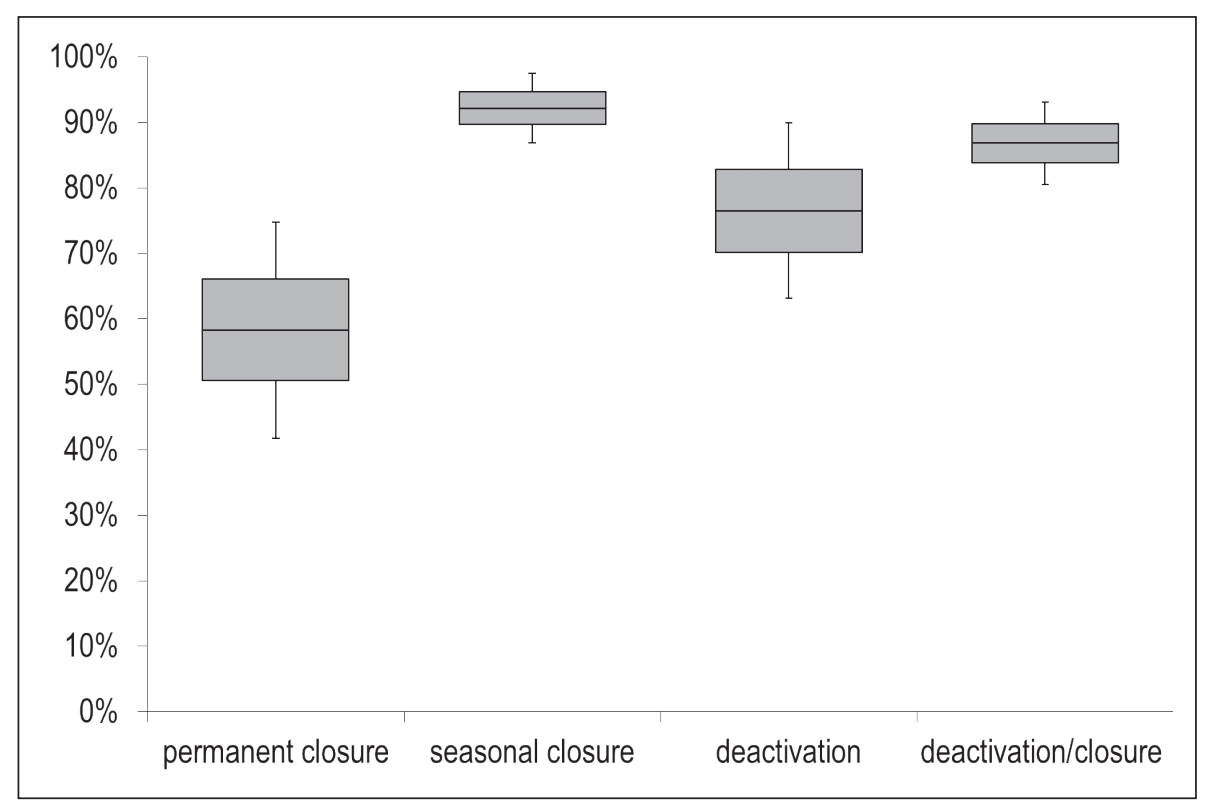

Fig. 3. Estimated percentage of reduction to traffic on single-lane unpaved roads during the first five weekends of the regular moose hunting season in northern Ontario, 2007-2012 (boxes represent +/- one standard error from mean; whiskers represent the $95 \%$ confidence interval for the mean). ecological effects from roads and road use (van der Ree et al. 2011), we examined the effectiveness of different approaches to reduce traffic volumes on resource roads. This examination focused on single-lane, unpaved roads in northern Ontario during weekends of the gun portion of the moose hunting season. Three general and two nested hypotheses were developed and tested from traffic counting data.

The results supported $H 1$ that road closure and/or deactivation treatments resulted in a significant reduction to traffic on the resource roads. More importantly, this reduction averaged about $78 \%$ with a $95 \%$ confidence interval ranging between roughly $60 \%$ to $90 \%$. These findings are encouraging for resource managers who can use closure and deactivation treatments on resource roads to help reduce, but not necessarily eliminate, traffic and potentially, the social and ecological effects from road use. For example, a sharp reduction to traffic volumes on resource roads will likely lower moose harvests in areas near roads (Shanley and Pyare 2011). This harvest reduction can benefit both the moose population and the economic livelihood of people who rely on guiding remote moose hunting trips.

No support was found for $\mathrm{H} 2$ that closure and deactivation treatments are most effective when road quality is poorest. As with other researchers (e.g., Boxall and McNab 2000, Haener et al. 2001), road quality was an important factor that influenced hunters' site selections and thus the traffic volumes during the moose hunting season. However, the mean predicted reductions to traffic for high- and low-quality roads were about equal at $78 \%$. The conclusions imply that while road quality significantly affected traffic during the moose hunting season, road quality was independent of the effectiveness of closure and/or deactivation treatments. It remains an empirical question whether this conclusion holds for contexts with multiple-lane resource roads and/or for traffic related to other activities. 
The results supported $H 3$ that differences existed in the relative effectiveness of the four closure and deactivation treatments at reducing traffic. Support was also found for $\mathrm{H} 3 \mathrm{a}$ that seasonal were relatively more effective than year-round road closures. While a seasonal closure was estimated to remove upwards of $92 \%$ of expected traffic, a year-round closure was estimated to remove less than $60 \%$ of expected traffic. This result is consistent with research in parts of Ontario and Alberta, where acceptance for resource road closures among residents was higher when the closure was temporary rather than year-round (McFarlane et al. 2007, Mihell and Hunt 2011).

A seasonal closure treatment was amongst the most while a year-round closure was amongst the least effective treatment to reduce traffic. This difference implies that one key factor for achieving high compliance with road closures is providing individuals with some opportunities to pursue their activity. We speculate that providing these opportunities increases social norms towards compliance with the closure because seasonal closures are relatively more acceptable than year-round road closures (McFarlane et al. 2007, Mihell and Hunt 2011).

Only some support existed for $\mathrm{H} 3 b$ that a combined deactivation and closure treatment would be most effective at reducing traffic on resource roads. While this combined treatment resulted in a significant reduction to traffic when compared to year-round road closures, we could not conclude that this treatment was more effective than deactivation and seasonal closure treatments. It is, apparently, overly simplistic to conclude that a combined closure and deactivation treatment will be more effective at reducing traffic than would a single closure or deactivation treatment. It appears that hunters who travel on a deactivated road are not heavily deterred by the added presence of a sign-based road closure.

Researchers should be aware of several factors that might influence the generality of the results and conclusions from this study. First, deactivated and closed treatments on single-lane roads are scarce in northern Ontario and these treatments tend to be spatially concentrated. Given a limited number of trafficcounting devices (30 in 2006), we typically selected sites that were spatially concentrated to limit field data collection costs for any given year and then moved to another area in the following year. Consequently, variations that could affect traffic and compliance across space and time (e.g., weather, fuel prices, social norms) were not independent of the treatment effects. While this limitation could have been overcome with a manipulative experiment, such manipulations could invoke public backlash and alter social norms (e.g., erode support for closure and deactivations of resource roads). Therefore, we encourage other individuals to conduct similar research to assess the generality of our conclusions.

Second, we focused only on traffic on single-lane, resource roads during the moose hunting season. We purposefully chose to monitor traffic during the moose hunting season during weekends because of the relatively high use of roads by recreationists during this time. This focus allowed us to investigate how the different treatments might affect recreationists and it discouraged use of roads by authorized users. Nevertheless, we encourage other researchers to conduct research that expands the contexts of this study (e.g., conduct research on larger-sized roads and traffic related to other activities).
Third, almost all deactivated and closed roads were created to manage social and economic concerns for nature-based tourism operators who sell primarily remote hunting and fishing trips to clientele. Some research results suggest that people are more accepting of road closures and deactivations for ecological rather than social reasons (Hendricks et al. 2001). Consequently, the level of compliance with year-round closures might increase if the rationale for the closure was different. We encourage researchers to conduct survey-based research to understand better how attitudes and social norms vary with different contexts and how attitudes and social norms affect compliance with resource road closures.

Fourth, the amount and location of enforcement activities during the moose hunting season were not adjusted for this study. From unpublished data, conservation officers in northern Ontario spent on average 565 hours per weekend day on enforcement activities besides training, outreach, and administration during the first five weeks of the 2011 and 2012 moose hunting season. This enforcement effort was about $60 \%$ higher than during the other days of the moose hunting season and over $130 \%$ higher than during days outside of the hunting season. During the hunting season in 2011 and 2012, northern Ontario conservation officers laid a total of 42 charges related to disobeying a sign. These statistics reveal that sign-based closures are enforced during the hunting season and that enforcement efforts peak during the period when traffic was monitored. Given that enforcement efforts affect compliance with regulations such as road closures (Sutinen and Kuperan 1999), our conclusions about the effectiveness of approaches to reduce traffic on closed roads depend on the these levels of enforcement activities. Therefore, additional research should be conducted on road closure compliance under conditions that vary the presence and effort of enforcement.

Even limiting our results to single-lane, resource roads provides important information for natural resource managers. Many multiple-lane, resource roads degrade into a single lane from low levels of use and encroaching vegetation. Likewise, many potential problems with road access in resource road settings often occur at the furthest extents of road networks that are almost always designed as single-lane roads. The results here provide practical advice in terms of the types of treatments that managers might wish to use to reduce traffic on these resource roads. The study also illustrated an effective approach to evaluate the effectiveness of treatments for reducing traffic.

\section{Acknowledgements}

We thank the Ontario Ministry of Natural Resources for providing the support for this research and Andy Lock for summarizing data. LH acknowledges support received from the Enhanced Forest Science Productivity Fund (EFPS Project 085-2-R2) and a larger project funded by the Forest Ecosystem Science Cooperative, NSERC CRD, NSERC Strategic Grant Program, the Ontario Ministry of Natural Resources, and the Canadian Forest Service that greatly helped in providing resources to help collect some traffic data. We also are very appreciative of the comments and suggestions from three reviewers and an Associate Editor. 


\section{References}

Bellis, E.D. and H.B. Graves. 1971. Deer mortality on a Pennsylvania interstate highway. J. Wildlife Manag. 35: 232-237.

Boxall, P.C. and B. MacNab. 2000. Exploring the preferences of wildlife recreationists for features of boreal forest management: A choice experiment approach. Can. J. For. Res. 30: 1931-1941.

Carpenter, S. R. et al. 2007. Understanding regional change: A comparison of two lake districts. Bioscience 57: 323-335.

Charry, B. and J. Jones. 2010. Traffic volume as a primary road characteristic impacting wildlife: a tool for land use and transportation planning. In P.J. Wagner, D. Nelson and E. Murray (eds.). Proceedings of the 2009 International Conference on Ecology and Transportation. pp. 159-172. Center for Transportation and the Environment, North Carolina University, Raleigh, NC.

Coffin, A.W. 2007. From roadkill to road ecology: A review of the ecological effects of roads. J. Transp. Geog. 15: 396-406.

Daigle, R. 2010. A summary of the environmental impacts of roads, management responses, and research gaps: A literature review. BC J. Ecosystems Manag. 10: 65-89.

Fahrig, L. and T. Rytwinski. 2009. Effects of roads on animal abundance: an empirical review and synthesis. Ecol. Society 14: 21 [online] Available at http://www.ecologyandsociety.org/vol14/iss1/art21/ [accessed July 102013 ].

Forman, R.T.T. 2002. Foreword. In K. J. Gutzwiller (ed.). Applying landscape ecology in biological conservation. pp. vii-x. Springer, New York.

Forman, R.T.T. et al. 2003. Road ecology - science and solutions. Island Press, Washington, D.C.

Haener, M.K., D. Dosman, W.L. Adamowicz and P.C. Boxall. 2001. Can stated preference methods be used to value attributes of subsistence hunting by Aboriginal Peoples? A case study in northern Saskatchewan. Amer. J. Agric. Econ. 83: 1334-1340.

Hammer, K. J. 2001. Gate-crashing: Road closure gates cannot effectively eliminate trespass. Unpublished manuscript. Available at http:// www.swanview.org/reports/Gate-Crashing-Report.pdf [accessed July 10, 2013]

Hendricks, W.W., R.H. Ramthum and D.J. Chavez. 2001. The effects of persuasive message source and content on mountain bikers' adherence to trail etiquette guidelines. J. Parks. Recr. Admin 19: 38-61.

Henschel, C. 2003. The road less travelled? A report on the effectiveness of controlling motorized access in remote areas of Ontario. Wildlands League and Sierra Legal Defence Fund, Toronto, ON.

Hunt, L.M. and S. Hosegood. 2008. The effectiveness of signs at restricting vehicle traffic: A case of seasonal closures on forest access roads. Can. J. For. Res. 38: 2306-2312.
Krinsky, I. and A.L. Robb. 1986. On approximating the statistical properties of elasticities. Rev. Econ. Stat. 68: 715-719.

McFarlane, B.L., R.C.G. Stumpf-Allen and D.O.T. Watson. 2007. Public acceptance of access restrictions to grizzly bear (Ursus arctos) country. Hum. Dim. Wild. 12: 275-287.

Mihell, K. and L.M. Hunt. 2011. Understanding residents' desired approaches to manage forest access roads: a case from northeastern Ontario, Canada. Can. J. For. Res. 41: 1808-1818.

[OMNR] Ontario Ministry of Natural Resources. 2001. Management guidelines for forestry and resource-based tourism. Queen's Printer for Ontario, Toronto, ON.

2007. Crown land recreation plan: Temagami integrated planning. Queen's Printer for Ontario, Toronto, ON.

Oxley, D.J., M.B. Fenton and G.R. Carmody. 1974. The effects of roads on populations of small mammals. J. Appl. Ecol. 11: 51-59.

Public Lands Act. 1990. (Ontario) s(28).

Robinson, C., P.N. Duinker and K.F. Beazley. 2010. A conceptual framework for understanding, assessing, and mitigating ecological effects of forest roads. Env. Rev. 18: 61-86.

Roedenbeck, I.A., L. Fahrig, C.S. Findlay, J.E. Houlahan, J.A. Jaeger, N. Klar, S. Kramer-Schadt and E.A. van der Grift. 2007. The Rauischholzhausen agenda for road ecology. Ecol. Society 12: 11 [online]. Available at http://www.ecologyandsociety.org/vol12/iss1/art11/ [accessed July 10, 2013].

Shanley, C.S. and S. Pyare. 2011. Evaluating the road-effect zone on wildlife distribution in a rural landscape. Ecosphere 2. Article 16.

Sutinen, J.G. and K. Kuperan. 1999. A socio-economic theory of regulatory compliance. Int. J. Soc. Econ. 26: 174-193.

US Department of Transportation. 2006. Traffic detector handbook: Third Edition - Volume 1. Research, Development, and Technology, Turner-Fairbank Highway Research Center, McLean, VA.

van der Ree, R., J.A.G. Jaeger, E.A. van der Grift and A.P. Clevenger. 2011. Effects of roads and traffic on wildlife populations and landscape function: Road ecology is moving toward larger scales. Ecol Soc. 16: 48 [online]. Available at http://www.ecologyandsociety.org/vol16/iss1/ art48/ [accessed Dec 20, 2013].

White, H. 1980. A heteroscedasticity-consistent covariance matrix estimator and a direct test for heteroscedasticity. Econometrica 48: 817-838.

Wilkie, D., E. Shaw, F. Rotberg, G. Morelli and P. Auzel. 2008. Roads, development, and conservation in the Congo Basin. Cons. Biol. 14: 1614-1622. 